\title{
Phytochemical screening, Antioxidant, Thrombolytic, a-amylase inhibition and cytotoxic activities of ethanol extract of Steudnera colocasiifolia K. Koch leaves
}

\author{
Mohammad Shah Hafez Kabir ${ }^{1}$, Mohammed Munawar Hossain ${ }^{1}$, Md. Imtiazul Kabir ${ }^{1}$, Md. Mominur Rahman ${ }^{1}$, Abul Hasanat ${ }^{1}$, \\ Talha Bin Emran², Md. Atiar Rahman ${ }^{3 *}$ \\ 'Department of Pharmacy, International Islamic University Chittagong, BANGLADESH. \\ 2Department of Pharmacy, BGC Trust University Bangladesh, Chittagong-4000, BANGLADESH. \\ ${ }^{3}$ Department of Biochemistry and Molecular Biology, University of Chittagong, Chittagong-4331, BANGLADESH.
}

\begin{abstract}
Objective: Present study aims to investigate both qualitative and quantitative phytochemicals presence, antioxidant, thrombolytic, $\alpha$-amylase and cytotoxic activity of a Bangladeshi plant Steudnera colocasiifolia K. Koch leaf ethanolic extract. Methods: Phytochemical screening was accomplished by using established methods. Thrombolytic assay was conducted through clot lysis method. Alpha amylase inhibition assay was made by modified enzyme inhibitory action and cytotoxicity was studied by brine shrimp lethality test. Data was analyzed by One Way Analysis of Variance (ANOVA) using statistical software Statistical Package for Social Science (SPSS, Version 22.0, IBM corporation, NY) followed by student ' $t$ ' test with GraphPad Prism Data Editor for Windows, Version 6.0 (GraphPad software Inc., San Diego, CA). Results: Primary screening shows the presence of major metabolites such as alkaloid, flavonoid, tannin, saponins, steroid, quinone, cellulose and glycosides while the quantitative analysis elicits the presence of magnificent amount of flavonoid (70.60 \pm 0.23 ), proanthocyanidin (64.46 \pm 0.58 ), flavonol $(71.22 \pm 0.07)$ and total antioxidant $(66.40 \pm 0.26)$ in the extract. The thrombolytic effect of $S$. colocasiifolia was found to be $35.16 \%$ and this extract
\end{abstract}

had good $\alpha$-amylase inhibitory activity $\left(\mathrm{IC}_{50}=2.16 \pm 0.06 \mathrm{mg} / \mathrm{ml}\right)$ as compared to Acarbose. The extract was found to have a $\mathrm{LC}_{50}$ value of $305.2 \mu \mathrm{g} / \mathrm{ml}$ in Brine shrimp lethality bioassay. Conclusion: Results demonstrate the Steudnera colocasiifolia has a very good prospect to be studied further for its extended antioxidative and $\alpha$-amylase inhibitory effects.

Key word: Steudnera colocasiifolia, Antioxidant, Thrombolytic, $\alpha$-amylase, Cytotoxic activity.

Correspondence :

Dr. Md. Atiar Rahman,

Associate Professor, Department of Biochemistry and Molecular Biology,

Faculty of Biological Sciences, University of Chittagong, Chittagong-4331, BANGLADESH.

Tel : 88-031-2606001-14 (Extn. 4334), Fax: 88-031-726310; Cell: +88-01711709084;

E-mail: atiar@cu.ac.bd

DOI: 10.5530/jyp.2016.4.15

\section{INTRODUCTION}

Plants and plant-derived sources not only provide us foodstuff, shelter but also they provide remedies for many years. Different chemical constituents contained in plant exhibit different activities for alleviating abnormal health of human or animals. Therefore, traditional medicine practitioners appreciate to use different parts of plant having several chemical constituents.

It is progressively being understood that a hefty portion of today's diseases are because of the 'oxidative stress' which produces enormous free radicals, causing tumor, atherosclerosis and cardiovascular illnesses. ${ }^{1}$ All human cells ensure themselves against free radical harm by catalysts such as ascorbic acid, tocopherol and glutathione. ${ }^{2}$ However, frequently these defensive systems are becoming upset by different neurotic techniques, and cell reinforcement supplements are imperative to battle oxidative harm. This is because much consideration has been controlled towards the improvement of ethnomedicine with solid cell reinforcement properties with low cytotoxicities.

Thrombus formed in the circulatory system due to the loss of homeostasis causes vascular blockage, atherothrombotic sicknesses, myocardial or cerebral localized necrosisultimately prompting death. Due to the associated high risk of bleeding intracranial hemorrhage, severe anaphylactic reaction and lacks specificity gastrointestinal bleeding or hypertension Streptokinase and Urokinase, tremendous efforts have also been directed towards the discovery and development of natural products such as the oral anticoagulants are derived from coumarin which is found in numerous plants like warfarins. ${ }^{3}$
Alpha-amylase is a well-known enzyme found in the pancreatic juice and saliva which breaks down large insoluble starch molecules to lower the levels of postprandial hyperglycemia ${ }^{4}$ Several inhibitors of $\alpha$-amylase have been isolated from different medicinal plants to serve as an alternative drug with increased potency and lesser adverse effects than existing synthetic drugs. ${ }^{5}$ However, the $\alpha$-amylase inhibitory effect of Steudnera colocasiifolia is still undiscovered. Additionally, the toxicity profile of even a potent plant source is inevitable to be recorded for fruitful use.

S. colocasiifolia K. Koch (family: Araceae) is an evergreen, creeping and ascending usually $30-50 \mathrm{~cm}$ long herb which is persistently cataphylls brown with leaf blade paler. It is habituated in dense forests, wet meadows, by streams, seasonally moist lowland forest. It is distributed in Bangladesh, India, Myanmar, Thailand and China. Locally it is used to treat injuries, cuts, snake and insect bites and skin ulcers. Whole plant extract of $S$. colocasiifolia has been found to show anti-arthritic and anti-inflammatory activities. ${ }^{6}$ This research investigated the phytochemical presence, antioxidative potential, thrombolytic effect, $a$-amylase inhibitory action and cytotoxic effect of S. colocasiifolia ethanolic extract.

\section{MATERIAL AND METHODS}

\section{Chemicals and reagents}

All the chemicals and reagents used in this research were of analytical grade. Ethanol, chloroform, sulfuric acid and hydrochloric acid were purchased from Merck (India). Gallic acid, Folin-Ciocalteau reagent and trichloroacetic acid (TCA) were procured from Sigma Chemicals Co. (P.O. Box 14508, St. Louis, MO 63178 USA). A 2, 2-diphenyl-1-picryl- 
hydrazyl (DPPH) and aluminium chloride were purchased from Fluka (Fluka chemie GmbH, CH-9471 Buchs). Ascorbic acid, Quercetin and Tannic acid were purchased from BDH Chemicals (BDH Chemicals Ltd. Poole, England). Ferric chloride, potassium ferricyanide, sodium hydroxide and sodium nitrite were purchased from Riedel-De Haen Ag, SeelzeHannover- Germany. Shimadzu Biospec 1601 UV visible spectrophotometer (Shimadzu, Japan) was used to measure the absorbance. Lyophilized streptokinase vial (1500000 IU) was purchased from Square Pharmaceuticals Ltd (Kaliakoir, Gazipur, Bangladesh). Vincristine sulfate ( $2 \mathrm{mg} /$ vial) was donated by Techno Drugs Limited Bangladesh.

\section{Plant material}

Fresh leaves of S. colocasiifolia were collected from Alu Tila, Khagrachari, Chittagong, Bangladesh in the month of September, 2014. It was authenticated by Dr. Sheikh Bokhtear Uddin, Professor, Department of Botany, University of Chittagong, Chittagong-4331, Bangladesh. A voucher specimen of the plant has been preserved to the departmental Herbarium with the ID. No: 1316 CTGUH.

\section{Preparation of Extract}

The leaves were dried for a period of 10 days under shade and ground with a locally available electrical hand grinder. The resulting powder $(250 \mathrm{~g})$ was soaked in $800 \mathrm{ml}$ of $98.5 \%$ ethanol for a week at room temperature with occasional stirring. The whole mixture was filtered with double layered cheese-cloth followed by a final filtration with Whatman filter paper (No.1) to obtain the filtrate which was concentrated and the filtrate thus obtained was concentrated using a rotary evaporator (RE 200, Bibby Sterling Ltd, UK) to get a viscous mass known as crude extract (2.8 g, 7\% yield) preserved at $4^{\circ} \mathrm{C}$ until in need for further use.

\section{Phytochemical Screening}

The freshly prepared crude extract was qualitatively tested for the presence of secondary metabolites especially saponins, flavonoids, steroids, alkaloids, carbohydrates, terpenoids, tannins, quinine, cellulose and glycosides through established methods. ${ }^{7}$

\section{In vitro Antioxidative Activity}

\section{DPPH free radical scavenging activity}

Free radical scavenging activity (2,2-diphenyl-1-picryl hydrazyl, DPPH) was carried out using the method of Brand-Williams. ${ }^{8}$ Different concentrations $(400,200,100,50,25$ and $12.5 \mu \mathrm{g} / \mathrm{mL})$ of $S$. colocasiifolia extract were dissolved in methanol and placed in different test tubes, and $3 \mathrm{~mL}$ of a $0.004 \% \mathrm{w} / \mathrm{v}$ methanol solution of DPPH was added to each test tube. Absorbance at $517 \mathrm{~nm}$ was determined after $30 \mathrm{~min}$ against a blank, and the percent inhibition activity was calculated from $[(\mathrm{A} 0-\mathrm{A} 1) / \mathrm{A} 0] \times 100$, where A0 is the absorbance of the control and A1 is the absorbance of the sample. Ascorbic acid was used as a reference standard and dissolved in methanol to make the stock solution with the same concentration. The control sample was prepared containing the same volume without any extract or reference drug. Methanol served as a blank. The inhibition curves were prepared and the half maximal inhibitory concentration $\left(\mathrm{IC}_{50}\right)$ values were calculated using linear regression analysis.

\section{Reducing capacity}

The reducing power of the extract was evaluated by the established method described by Oyaizu with slight modification. ${ }^{9}$ Different concentrations of rhizome extract of S. colocasiifolia $(62.5,125,250,500$, and $1000 \mu \mathrm{g} / \mathrm{mL}$ ) in $1 \mathrm{~mL}$ of distilled water were mixed with phosphate buffer $(2.5 \mathrm{~mL}, 0.2 \mathrm{M}, \mathrm{pH}=6.6)$ and potassium ferricyanide [ $\mathrm{K}_{3} \mathrm{Fe}(\mathrm{CN}) 6$ ] $(2.5 \mathrm{~mL}, 1 \% \mathrm{w} / \mathrm{v})$. The mixture was incubated at $50^{\circ} \mathrm{C}$ for $20 \mathrm{~min}$. After incubation, $2.5 \mathrm{~mL}$ of $10 \%$ trichloroacetic acid solution was added to each tube and the mixture was centrifuged at $3000 \mathrm{rpm}$ for $10 \mathrm{~min}$. Subsequently, $5 \mathrm{~mL}$ of the upper layer solution was mixed with $5 \mathrm{~mL}$ of distilled water and $1 \mathrm{~mL}$ of ferric chloride solution $(0.1 \% \mathrm{w} / \mathrm{v})$, and the absorbance was measured at $700 \mathrm{~nm}$. The reducing power of the extract was linearly proportional to the concentration of the sample. Ascorbic acid was taken as a reference standard. Phosphate buffer ( $\mathrm{pH}$ 6.6) was used as a blank solution.

\section{Determination of total phenolic content}

The total phenolics content of the extract was estimated according to the method described by Singleton and Rossi. ${ }^{10}$ The phenolic concentration of extracts was evaluated from a gallic acid calibration curve. To prepare a calibration curve, $0.5 \mathrm{~mL}$ aliquots of $12.5,25,50,100,200$, and $400 \mu \mathrm{g} / \mathrm{mL}$ methanolic gallic acid solutions were mixed with $2.5 \mathrm{~mL}$ Folin-Ciocalteu reagent (diluted ten-fold) and $2.5 \mathrm{~mL}(75 \mathrm{~g} / \mathrm{L})$ sodium carbonate. After incubation at $25^{\circ} \mathrm{C}$ for $30 \mathrm{~min}$, the quantitative phenolic estimation was performed at $765 \mathrm{~nm}$ against reagent blank by UV Spectrophotometer 1650. The calibration curve was constructed by putting the value of absorbance vs. concentration. A similar procedure was adopted for the extract as above described in the preparation of calibration curve. All determinations were performed in triplicate. Total phenolic content was expressed as milligrams of gallic acid equivalent (GAE) per g of extract.

\section{Determination of total flavonoid content}

Total flavonoid content of ethanol extract was evaluated with method developed by Brighente et al. ${ }^{11}$ One $\mathrm{ml}$ of $S$. colocasiifolia extracts or standard of different concentrations was taken in a test tube and $3 \mathrm{ml}$ of methanol was added. Then $200 \mu \mathrm{l}$ of $10 \%$ aluminium chloride solution was added into the same test tube followed by the addition of $200 \mu \mathrm{l}$ of $1 \mathrm{M}$ potassium acetate. Finally, $5.6 \mathrm{ml}$ of distilled water was mixed with the reaction mixture. The reaction mixture was then incubated for $30 \mathrm{~min}$ at room temperature to complete the reaction. Then the absorbance of the solution was measured at $415 \mathrm{~nm}$ using a spectra photometer against blank. Methanol was served as blank. The Total content of flavonoid compounds in S. colocasiifolia extract was expressed in $\mathrm{mg} / \mathrm{g}$ quercetin equivalent (QE).

\section{Total flavonol}

Total flavonol content was determined by adopting the protocol described by Kumar et al. ${ }^{12}$ The reaction mixture consisted of $2.0 \mathrm{ml}$ of the sample, $2.0 \mathrm{ml}$ of $\mathrm{AlCl}_{3}$ prepared in ethanol and $3.0 \mathrm{ml}$ of $(50 \mathrm{~g} / \mathrm{L})$ sodium acetate solution. The absorbance at $440 \mathrm{~nm}$ was measured after $2.5 \mathrm{~h}$ at $20^{\circ} \mathrm{C}$. Total flavonol content was calculated as $\mathrm{mg} / \mathrm{g}$ of quercetin equivalent from the calibration curve using the equation: $Y=0.0255 \mathrm{x}$, $R^{2}=0.9812$, where $x$ is the absorbance and $Y$ is the quercetin equivalent.

\section{Determination of total proanthocyanidin}

Total proanthocyanidin was determined based on the procedure of Oyedemi et al..$^{13}$ To $0.5 \mathrm{ml}$ of $1 \mathrm{mg} / \mathrm{ml}$ of the extract solution was added $3 \mathrm{ml}$ of vanillin-methanol $(4 \% \mathrm{v} / \mathrm{v})$ and $1.5 \mathrm{ml}$ of hydrochloric acid and vortexed. The mixture was allowed to stand for $15 \mathrm{~min}$ at room temperature and the absorbance was taken at $500 \mathrm{~nm}$. Total proanthocyanidin content was evaluated at a concentration of $0.1 \mathrm{mg} / \mathrm{ml}$ and expressed as catechin equivalent $(\mathrm{mg} / \mathrm{g})$ using the calibration curve equation: $\mathrm{Y}=0.5825 \mathrm{x}, \mathrm{R}^{2}=0.9277$, where $x$ is the absorbance and $Y$ is the catechin equivalent.

\section{Total tannin content}

The tannins were determined using the Folin-ciocalteu Phenol reagent as reported by Amorim..$^{14}$ Briefly, $0.1 \mathrm{ml}$ of the sample extract is added with $7.5 \mathrm{ml}$ of distilled water and then added $0.5 \mathrm{ml}$ of Folin-ciocalteu Phenol reagent, $1 \mathrm{ml}$ of $35 \%$ sodium carbonate solution and dilute to $10 \mathrm{ml}$ with distilled water. The mixture was shaken well, kept at room temperature 
for $30 \mathrm{~min}$ and absorbance was measured at $725 \mathrm{~nm}$. Blank was prepared with water instead of the sample. A set of standard solutions of tannic acid is read against a blank. The results of tannins are expressed in terms of tannic acid in $\mathrm{mg} / \mathrm{g}$ of extract. Total tannin content was determined as $\mathrm{mg}$ of tannic acid equivalent per gram using the equation obtained from a standard tannic acid calibration curve $\mathrm{Y}=4.5692 \mathrm{x}-0.2538, \mathrm{R}^{2}=0.9953$, where $\mathrm{y}$ is the absorbance and $\mathrm{x}$ is the tannic acid equivalent.

\section{Total antioxidant capacity}

Total antioxidant activity of the fractions was evaluated by the Phosphomolybdate method using Ascorbic acid (AA) as a standard..$^{15}$ The assay is based on the reduction of Mo (VI)-Mo (V) by the extract and subsequent formation of a green phosphate/Mo (V) complex at acidic $\mathrm{pH}$. An aliquot of $0.3 \mathrm{~mL}$ extract was combined with $3 \mathrm{ml}$ of reagent solution (0.6 M sulfuric acid, $28 \mathrm{mM}$ sodium phosphate and $4 \mathrm{mM}$ ammonium molybdate). The tubes containing the reaction solution were incubated at $95^{\circ} \mathrm{C}$ for $90 \mathrm{~min}$. After the samples had cooled to room temperature, the absorbance of the solution was measured at $695 \mathrm{~nm}$ against blank using a spectrophotometer. Methanol $(0.3 \mathrm{~mL})$ in the place of extract is used as the blank. Ascorbic acid equivalents were calculated using standard graph of AA. The experiment was conducted in triplicates and values are expressed as equivalent of ascorbic acid in mg per $g$ of extract.

\section{In vitro Thrombolytic Activity}

\section{Blood sample collection}

Twenty milliliter of whole blood (vein) was drawn from young and healthy human volunteers $(n=20)$ without a history of oral contraceptive or anticoagulant therapy using a protocol approved by the Institutional Ethical Review Board. An earlier consent form was supplied to the volunteers for collection of blood samples from human volunteers. A $500 \mu \mathrm{L}$ of blood was transferred to each of the eight previously weighed micro centrifuge tubes to form clots.

\section{Clot lysis}

Clot lysis test was performed according to the method described by Prasad et al. ${ }^{16}$ In the commercially available lyophilized streptokinase vial (1 $500000 \mathrm{IU}) 5 \mathrm{~mL}$ sterile distilled water was added and mixed properly. This suspension was used as a stock solution from which appropriate dilution was made. Five milliliter of venous blood was drawn from the healthy volunteers $(n=20)$ without the history of oral contraceptive or anticoagulant therapy and was distributed $(0.5 \mathrm{~mL} /$ tube $)$ to each twenty previously weighed sterile micro centrifuge tube and incubated at $37^{\circ} \mathrm{C}$ for $45 \mathrm{~min}$ to form the clot. After the clot formation, serum was completely removed without disturbing the clot and each tube having clot was again weighed to determine the clot weight. A volume of $100 \mu \mathrm{L}$ of ethanol extract $(10 \mathrm{mg} / \mathrm{mL})$ was added to each micro centrifuge tube containing pre weighed clot. As a positive control, $100 \mu \mathrm{L}$ of streptokinase and as a negative control $100 \mu \mathrm{L}$ of distilled water were separately added to the control tube numbered. All the tubes were then incubated at $37^{\circ} \mathrm{C}$ for $90 \mathrm{~min}$ and observed for clot lysis. After incubation, fluid released was removed and tubes were again weighed to observe the difference in weight after clot disruption. Difference obtained in weight taken before and after clot lysis was expressed as percentage of clot lysis.

\section{In vitro a-amylase inhibitory activity}

This study was performed by a modified starch iodine protocol as described by Hossan et al. ${ }^{17}$ In short, $1 \mathrm{~mL}$ of plant extract or standard of different concentration $(2,1,0.5 \mathrm{mg} / \mathrm{mL})$ was taken in prelabeled test tubes. The reaction mixture contained $20 \mu \mathrm{l}$ of $\alpha$-amylase solution $(10 \mathrm{mg} / \mathrm{ml})$, phosphate buffer $(0.02 \mathrm{M}, \mathrm{pH}=7.0)$ with $0.006 \mathrm{M} \mathrm{NaCl}(0.4 \mathrm{ml})$ was added to each test tube and incubated for $10 \mathrm{~min}$ at $37^{\circ} \mathrm{C}$. After the incubation $200 \mu \mathrm{L}$ of $1 \%$ starch solution was added to each test tube and the mixture was re-incubated for $1 \mathrm{~h}$ at $37^{\circ} \mathrm{C}$. Then $200 \mu \mathrm{L}$ of $1 \%$ iodine solution was added to each test tube and after that, $10 \mathrm{~mL}$ distilled water was added. Absorbance of the mixture was taken at $565 \mathrm{~nm}$. Sample, substrate and $\alpha$-amylase blank were undertaken under the same conditions. Each experiment was done in triplicate. $\mathrm{IC}_{50}$ value was calculated by using regression analysis.

$$
\% \alpha \text {-amylase inhibition }=\left[1-\frac{(\mathrm{SA}-\mathrm{SBB})-\mathrm{SMB}}{\mathrm{AAB}}\right] \times 100 \%
$$

$\mathrm{SA}=$ Sample absorbance, $\mathrm{SMB}=$ Sample blank, $\mathrm{SBB}=$ Substrate blank, $\mathrm{AAB}=\alpha$-Amylase blank.

\section{In vitro cytotoxicity test}

Cytotoxicity of the extract was tested by the brine shrimp lethality assay. ${ }^{18}$ Artificial sea water was prepared by dissolving $38 \mathrm{~g}$ of $\mathrm{NaCl}$ $(3.8 \%)$ in $1000 \mathrm{ml}$ of distilled water and was filtered to obtain a clear solution. The dried cysts of the brine shrimps were hatched in artificial seawater with strong aeration for 48 hours. Ethanol extract was dissolved in sea water with DMSO $(<0.01 \%)$ and transferred to test tubes to obtain concentrations of $25,50,100,200,300$ and $400 \mu \mathrm{g} / \mathrm{ml}$ in $5 \mathrm{ml}$ artificial sea water with 20 nauplii in each test tube. Standard drug Vincristine sulfate was used as positive control at concentrations of 5, 2.5, 1.25, 0.625, and $0.312 \mu \mathrm{g} / \mathrm{ml}$. Control test tubes were subjected to DMSO in artificial seawater at the same concentration as it was made for samples. After $24 \mathrm{~h}$ incubation at $25-30^{\circ} \mathrm{C}$, the number of viable nauplii was counted using a magnifying glass. The percent (\%) mortality was calculated using the following formula:

$$
\% \text { Mortality }=\frac{\mathrm{Nt}}{\mathrm{N} 0} \times 100
$$

Where, Nt $=$ Number of dead nauplii after 24 hrs of incubation, N0 $=$ Number of total nauplii transferred $(n=20)$. The Median lethal concentration $\left(\mathrm{LC}_{50}\right)$ was then determined.

\section{Statistical analyses}

All analyses were carried out in triplicates and values were presented as Mean \pm SEM. Data was analyzed by One Way Analysis of Variance (ANOVA) using statistical software Statistical Package for Social Science (SPSS, Version 22.0, IBM corporation, NY) followed by student ' $\mathrm{t}$ ' test with GraphPad Prism Data Editor for Windows, Version 6.0 (GraphPad software Inc., San Diego, CA). P $<0.05$ was considered as statistically significant.

\section{RESULTS}

\section{Primary phytochemical Screening}

Data for primary phytochemical screening are shown in Table 1. Results indicated that the extract contains alkaloids, carbohydrates, phenols, tannin, flavonoids, saponins, steroids, quinone, cellulose and glycosides.

\section{In vitro Antioxidant Activity $D P P H$ radical scavenging activity}

Results for the free radical scavenging activity of ethanol extract of S. colocasiifolia are shown in Figure 1. The extract showed a dose dependent radical scavenging effect in DPPH assay. The half inhibition concentration $\left(\mathrm{IC}_{50}\right)$ for free radicals achieved by the extract is $39.01 \mu \mathrm{g} / \mathrm{ml}$ which is statistically significant compared to that $\left(\mathrm{IC}_{50} 8 \mu \mathrm{g} / \mathrm{ml}\right.$ ) of ascorbic acid.

\section{Reducing capacity}

Results showed a proportional increase of reducing power with the increase of extract concentration (Figure 2). Increase in absorbance of the reaction mixture indicates the increase in the reducing power of the sample. 

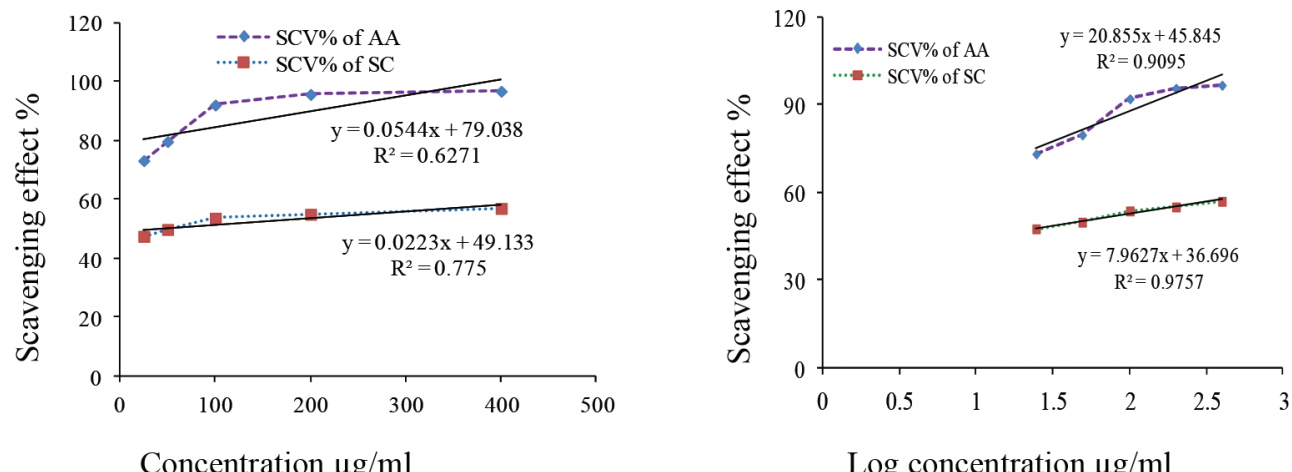

Log concentration $\mu \mathrm{g} / \mathrm{ml}$

Figure 1: DPPH radical scavenging activity of S. colocasiifolia leaves; (a) Concentration vs. scavenging effect, (b) Log concentration vs. scavenging effect (IC ${ }_{50}$ was calculated from this plot).
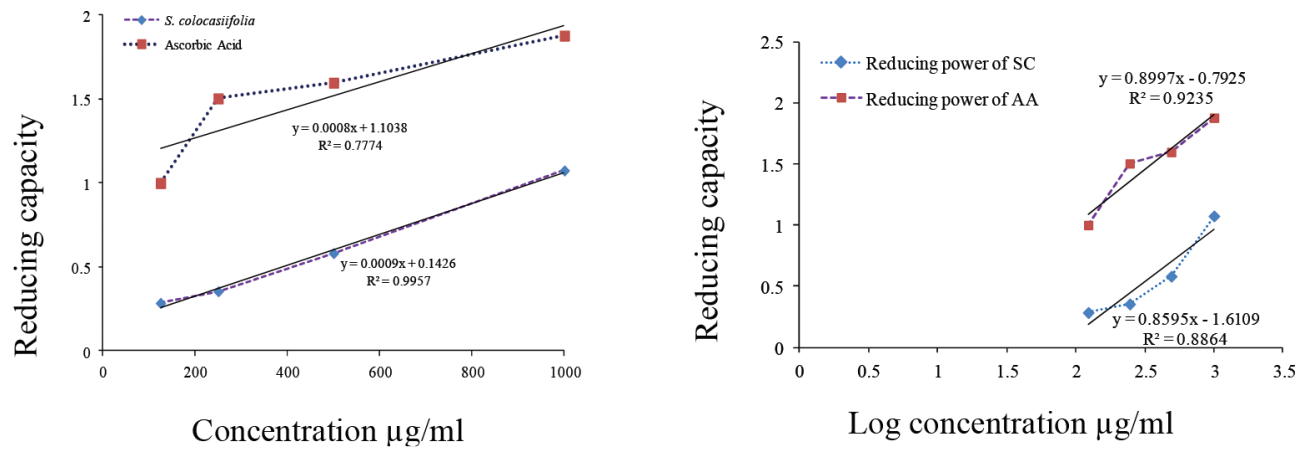

Figure 2: Reducing capacity of the ethanolic extract of S. colocasiifolia leaves; (a) Reducing capacity vs. concentration, (b) Reducing capacity vs. Log concentration $\left(\mathrm{IC}_{50}\right.$ was calculated from this plot.

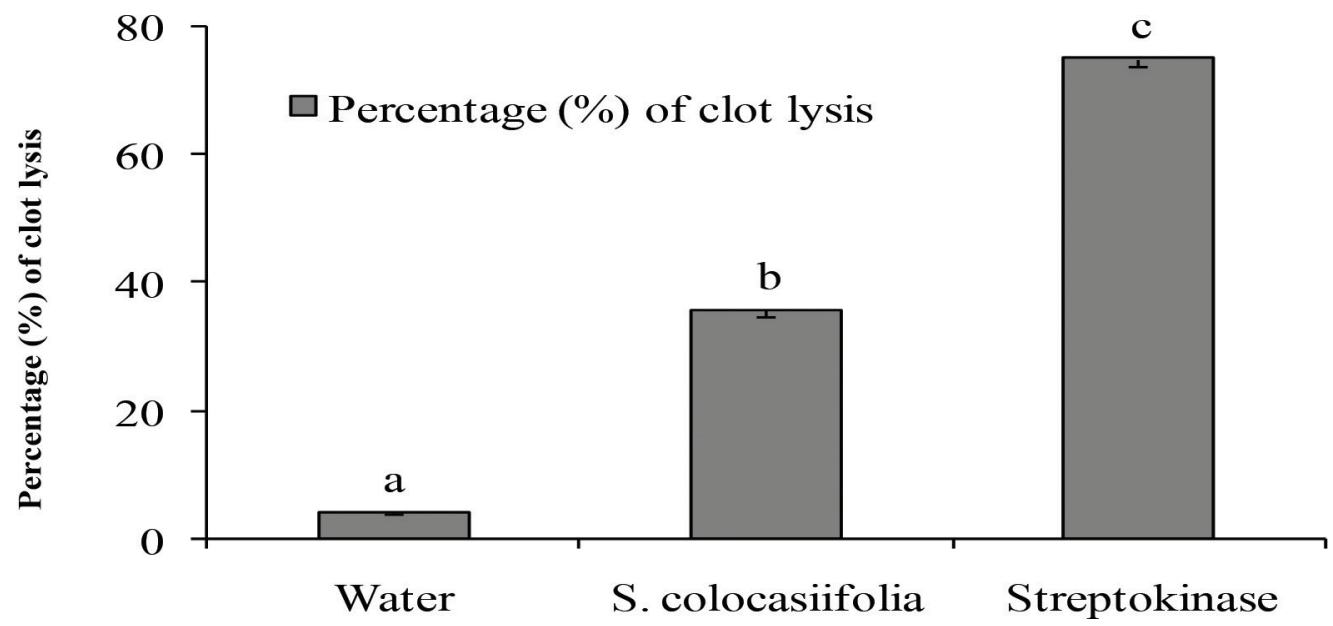

Figure 3: Thrombolytic activities of ethanolic extract of S. colocasiifolia leaves. Values are presented as mean \pm SEM for 20 volunteers. Data were processed by paired t-test analysis by using SPSS for windows, version 22.0, followed by Dunnet test as compared to control (positive and negative). ${ }^{\mathrm{a}-\mathrm{c}}$ superscript letters on outside-end of the line bars are significantly different from each other. 


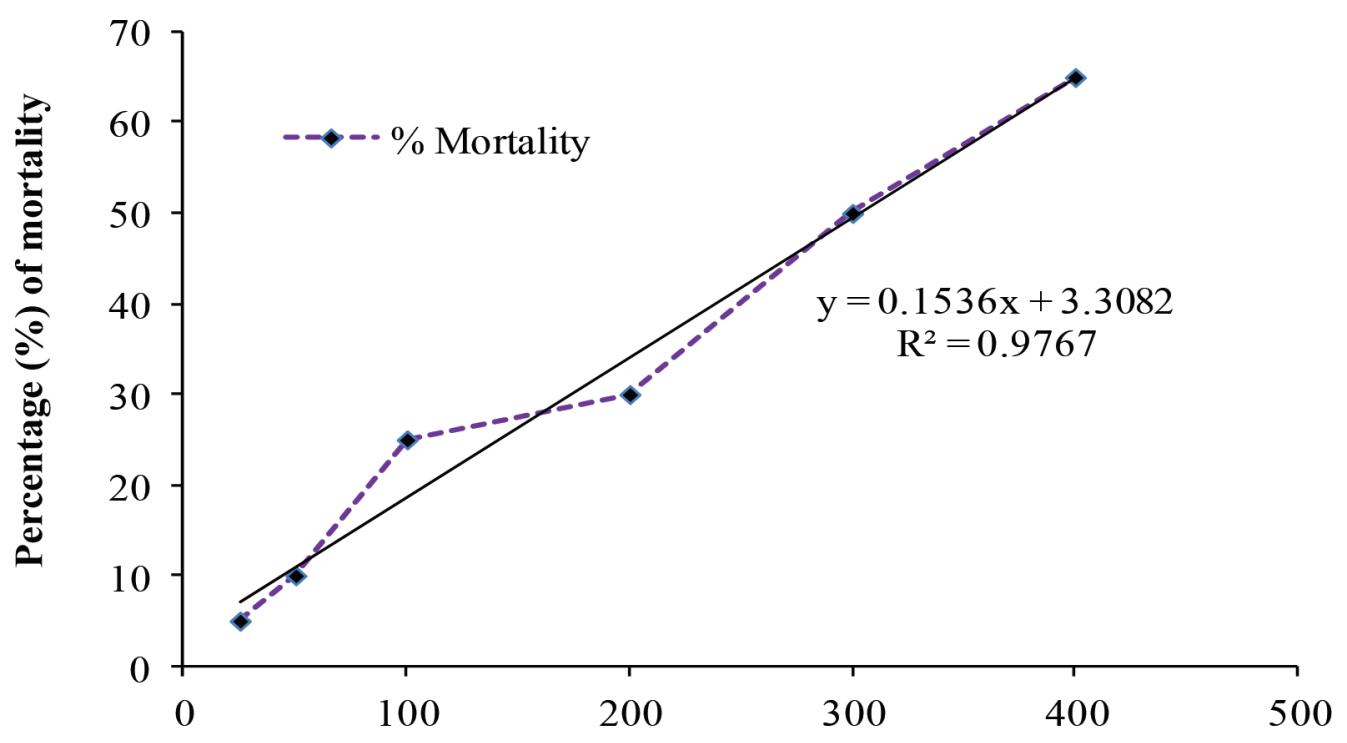

Concentration $\mu \mathrm{g} / \mathrm{ml}$

Figure 4: Effects of various concentrations of ethanol extract of S. colocasiifolia leaves on the viability of brine shrimp nauplii after $24 \mathrm{hr}$ incubation.

\section{Table 1: Phytochemical Analysis of leaf extract of S. colocasiifolia}

\begin{tabular}{cc}
\hline Secondary metabolite & Ethanol extract \\
\hline Alkaloids & + \\
Carbohydrate & + \\
Phenol & + \\
Tannin & + \\
Flavonoid & + \\
Saponins & + \\
Steroid & + \\
Quinone & + \\
Cellulose & + \\
Glycosides & + \\
\hline
\end{tabular}

Note: $(+)=$ Present, $(-)=$ Absent.

Table 2: Phytochemicals of ethanolic extract of S. colocasiifolia

\begin{tabular}{cc}
\hline Phytochemicals (mg/g) & S. colocasiifolia (ethanol) \\
\hline Total Phenol (mg Gallic acid /g) & $37.56 \pm 0.59$ \\
Total Flavonoid (mg Quercetin/g) & $70.60 \pm 0.23$ \\
Total Flavonol (mg Quercetin/g) & $71.22 \pm 0.07$ \\
Total Proanthocyanidin (mg Catechin/g) & $64.46 \pm 0.58$ \\
Total Tannin (mg Tannic acid/g) & $06.17 \pm 0.71$ \\
Total Antioxidant (mg Ascorbic acid/g) & $66.40 \pm 0.26$ \\
\hline
\end{tabular}

Values are the mean of triplicate experiments and represented as mean \pm SEM $(n=3)$.

\section{Quantitative determination of phytochemical contents}

Data for total phenolic, total flavonoid, total flavonols, total proanthocyanidin, total tannin and total antioxidant capacity has been summarized in Table 2. Data shows that highest amount of total flavonols, total flavonoids and total antioxidants are present in the extract. However, very promising amount of proanthocyanidin was also existed in S. colocasiifolia ethanol extract (SCEEx).
Table 3: $\mathrm{IC}_{50}$ values $(\mathrm{mg} / \mathrm{mL})$ for S. colocasiifolia ethanolic leave extract and Acarbose in a-amylase inhibitory assay

\begin{tabular}{cccc}
\hline Treatment & $\begin{array}{c}\text { Concentration } \\
(\mathrm{mg} / \mathrm{mL})\end{array}$ & \% Inhibition & $\mathrm{IC}_{50}$ value $(\mathrm{mg} / \mathrm{mL})$ \\
\hline & 0.50 & $23.81 \pm 0.35$ & \\
S. colocasiifolia & 1.00 & $38.29 \pm 0.38$ & $2.16 \pm 0.06^{\mathrm{b}}$ \\
& 2.00 & $46.46 \pm 0.26$ & \\
Acarbose & 0.25 & $15.89 \pm 1.11$ & \\
& 0.50 & $26.05 \pm 0.43$ & $0.91 \pm 0.01^{\mathrm{a}}$ \\
& 1.00 & $55.38 \pm 0.88$ & \\
\hline
\end{tabular}

Values are the mean of triplicate experiments and represented as mean \pm SEM $(n=3)$. Values in the same column with different ${ }^{a} \&$ b superscript letters are significantly different $(\mathrm{P}<0.05)$ from each other. Student's t test was performed to analyze this data set.

\section{In vitro thrombolytic activity}

In thrombolytic activity assay, addition of $100 \mu \mathrm{l}$ streptokinase as positive control to the clots showed $75 \pm 1.08 \%$ lysis of clot. On the other hand, distilled water treated as negative control exhibited a negligible percentage of lysis which was $4.19 \%$. The mean difference in clot lysis percentage between positive and negative control was found statistically very significant $(\mathrm{P}<0.05)$. In this study, the crude SCEEx exhibited $35.16 \pm 0.97 \%$ of thrombolytic activity. The data are shown in Figure 3.

In vitro a-amylase inhibitory activity

Alpha amylase inhibitory action of SCEEx is shown in Table 3. It is noted that both SCEEx and acarbose significantly inhibited $\alpha$-amylase activity in a dose dependent manner.

\section{In vitro Brine Shrimp lethality bioassay}

Cytotoxic effect of the SCEEx is summarized in the Figure 4. The $\mathrm{LC}_{50}$ values for SCEEx and Vincristine sulfate were found to be $305.20 \mu \mathrm{g} / \mathrm{ml}$ and $0.74 \mu \mathrm{g} / \mathrm{ml}$, respectively. 


\section{DISCUSSION}

Plants polyphenols greatly contribute to defend the common complications involved with free radicals or reactive oxygen species. Structural and quantitative variations of phenolic classes strongly differentiate their effects as free radical scavengers and potentials as food antioxidants. ${ }^{19}$ This study reflects the quantitative variations of phenolics as total flavonol $>$ total flavonoid $>$ total antioxidant $>$ total proanthocyanidin $>$ total phenol $>$ total tannin indicating a strong radical scavenging, hydrogen benefactors, and singlet oxygen quenching capability of SCEEx. ${ }^{20}$ The electron donation ability of natural products can be measured by 2,2-diphenyl-1- picrylhydrazyl radical (DPPH) purple-coloured solution bleaching. ${ }^{21}$ The method is based on scavenging of DPPH through the addition of a radical species or antioxidant that decolourizes the DPPH solution. The degree of colour change is proportional to the concentration and potency of the antioxidants. A large decrease in the absorbance of the reaction mixture indicates significant free radical scavenging activity of the compound under test. ${ }^{22}$ In the present study SCEEx showed significantly higher inhibition percentage and positively correlated with total phenolic content. Results of this study suggest that the plant extract contain phytochemical constituents that are capable of donating hydrogen to a free radical to scavenge the potential damage.

The activities of antioxidants have been attributed to various mechanisms such as prevention of chain initiation, reducing capacity and radical scavenging. ${ }^{23}$ The antioxidants action of SCEEx has been reflected through their reduction of $\mathrm{Fe}^{3+}$-ferricyanide complex to the ferrous form making an evidence of the reducing power. The ferric reducing power activity of SCEEx seems to be due to the presence of existence of polyphenols. The reducing capacity of plant extract may serve as a significant indicator of its potential antioxidant activity. ${ }^{24}$

Thrombolytic drugs block the pathway of thrombus formation with the help of plasmin, a natural fibrinolytic agent, that lyses clot by breaking down the fibrinogen and fibrin contained in a clot. ${ }^{25}$ Commercially available thrombolytic drugs especially streptokinaseforms a 1:1 stoichiometric complex with plasminogen fostering the conversion of additional plasminogen to plasmin and thereby increasing clot lysis. ${ }^{26}$ Scientists reported that phytochemical metabolites especially flavonoids affect thrombosis and cardiovascular disease by interfering with platelet activation, a potential risk factor for cardiovascular disease. High content of flavonoids (70.60 $\pm 0.23 \mathrm{mg}$ Quercetin/g) of SCEEx is very consistent with previous documents as well as basic hypothesis indicating SCEEx the role of flavonoids for clot lysis activity in this research. ${ }^{27}$

The inhibition of $\alpha$-amylase, which hydrolyzes starch and related polysaccharides, involved in the breakdown of starch has been suggested to be a useful approach to the management and prevention of type 2 diabetes. ${ }^{28}$ Amylase inhibitors contain substances that prevent dietary starch from being absorbed by the body. In recent years, extensive investigation on pharmacological actions of plant metabolites focuses that the main protective effect of plant substances has been attributed to the presence of antioxidants such as flavonoids, isoflavone, flavones, anthocyanin, catechin and isocatechin. ${ }^{29}$ Strong antioxidative effect led by highest content of flavonols and flavonoids in the studied plant extract might be the contributory factors for $\alpha$-amylase action of SCEEx.

The brine shrimp lethality bioassay is found to have a good correlation with cytotoxic activity in some human solid tumors and with pesticidal activity, and led to the discovery of new class of natural pesticides and active antitumoral agents. ${ }^{18}$ Hypothetically LC $_{50}$ values less than $250 \mu \mathrm{g} /$ $\mathrm{ml}$ is usually considered toxic and very potential for further investigation to verify the effect of the extract as anticancer, antitumor and pesticidal agent. ${ }^{30}$ However, SCEEx, was found to have a $\mathrm{LC}_{50}$ value of $305.2 \mu \mathrm{g} / \mathrm{ml}$, which is not toxic for formulation as therapeutics.

\section{CONCLUSION}

The results stated above showed that the ethanolic extract of $S$. colocasiifolia possessed significant antioxidative effects in all the models. Among other activities it is evident that $S$. colocasiifolia could be prospective to be investigated further for its extended $\alpha$-amylase inhibitory effects in in vivo system.

\section{ACKNOWLEDGEMENTS}

Authors are grateful to the authority of International Islamic University for providing the facilities to conduct this research work.

\section{CONFLICT OF INTEREST}

The authors declare that they have no conflict of interest.

\section{ABBREVIATIONS USED}

SCEEx : S. colocasiifolia ethanol extract; DPPH: 2,2-diphenyl-1- picrylhydrazyl radical; QE: Quercetin equivalent; LC: Lethal concentration; IC: Inhibition concentration.

\section{ABOUT AUTHORS}

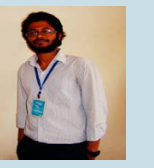

Mohammad Shah Hafez Kabir: Has completed his Bachelor of Pharmacy (Honours) at 2015 from International Islamic University Chittagong Bangladesh and working as research assistant in GUSTO (A Research Group). He is working on Phytomedicine and Drug-drug interaction to coorelate the structure activity relationship with the help of molecular docking. He is the trainer at SAGE Research training centre. He has published more than 38 papers in ISI, Pubmed and Scopus indexed journals. He has been serving as a reviewer in different journals.

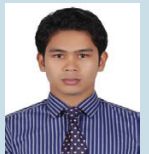

Mohammed Munawar Hossain: Has completed his Bachelor of Pharmacy (Honours) at 2015 from International Islamic University Chittagong, Bangladesh and working as research assistant in GUSTO (A Research Group). He is working on Phytomedicine and Drug-drug interaction. And to develop different dry lab methods to co-related the activity with the help of molecular docking. He has published more than 15 papers in reputed journals, where many papers are ISI, Pubmed and Scopus indexed.

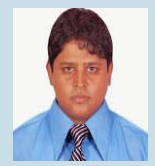

Md. Imtiazul Kabir: Has completed his Bachelor of Pharmacy in June, 2015 from International Islamic University Chittagong from the Faculty of Engineering and Applied Science. Currently he is working as a research apprentice Under Dr. Md. Atiar Rahman, Associate professor, Department of Biochemistry and Molecular Biology, University of Chittagong, Chittagong, Bangladesh. Md. Kabir has experiences in the area of Pharmacognosy and pharmacological implementation of Natural Products. 
Md. Mominur Rahman: Is Assistant Professor in Department of Pharmacy, International Islamic University Chittagong, Bnagladesh. He completed his B. Pharm (Honours) from Department of Pharmacy, University of Science \& Technology Chittagong and Master of Science in Pharmaceutical Science from University of Asia Pacific. He is working on Phytomedicine specially on neuropharmacology. He has published more than 40 papers in ISI, Pubmed and Scopus indexed journals. He has been serving as a reviewer in different journals.

Abul Hasanat: Is a M. Pharm student at the State University of Bangladesh, and he completed his under graduation in Bachelor of Pharmacy at 2015 from International Islamic University Chittagong, Bangladesh and working as research assistant in GUSTO (A Research Group). He is working on Phytomedicine and Public Health concern. He has published more than 38 papers in reputed journals, where many papers are ISI, Pubmed and Scopus indexed.

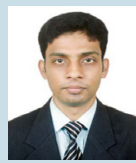

Talha Bin Emran: Is B. Sc. (Hon's), M. S. (Biochemistry and Molecular Biology, University of Chittagong). Talha Bin Emran is now a doctora student at Kanazawa University, Japan. He has been working as a Lecturer (Study Leave), in the Department of Pharmacy, BGC Trust University, Bangladesh from January 2012 to till the date. He is working to develop novel vaccine candidates against infectious diseases such as malaria, which is outstanding among domestic pharmaceutical institutes. He is also focusing on the biology of malaria parasites for innovative drug development.

Dr. Md. Atiar Rahman: Has been working as an associate professor in the Department of Biochemistry and Molecular Biology at the University of Chittagong. Dr. Rahman has had his B.Sc honours and M.Sc in Biochemistry from the University of Dhaka, PhD from United Graduate School of Agricultural Science Ehime University, Japan and Post doctoral degree from KwaZulu Natal University, South Africa. He is a principal investigator of the Laboratory of Complentary and Alternative Medicine and Natural Product Research of the aforementioned department. Currently he is carrying out the research to explore the novel and indigenous sources of phytomedicinal components as alternative therapeutics for noncommunicable chronic diseases especially type 2 diabetes and chemical induced acute hepatic toxicity through intervention in animal models.

\section{REFERENCES}

1. Braca A, Sortino C, Politi M, Morelli I, Mendez J. Antioxidant activity of flavonoids from Licania licaniaeflora. J Ethnopharmacol. 2002;79(3):379-381.

2. Valko M, Jomova K, Rhodes CJ, Kuca K, Musilek K. Redox- and non-redoxmetal-induced formation of free radicals and their role in human disease. Arch Toxicol. 2016;90(1):1-37.

3. Lee HS. How safe is the readministration of streptokinase. Drug Safety 1995;13(2):76-80.

4. Cheng J, Zhou ZW, Sheng HP, He LJ, Fan XW, He ZX, et al. An evidence-based update on the pharmacological activities and possible molecular targets of $L y$ cium barbarum polysaccharides. Drug Des Devel Ther. 2015;(9):33-78.

5. Pereira AC, Pereira AB, Moreira CC, Botion LM, Lemos VS, Braga FC, et al Hancornia speciosa Gomes (Apocynaceae) as a potential anti-diabetic drug. J Ethnopharmacol. 2015;161:30-5.

6. Hossain MM, Kabir MSH, Hasanat A, Kabir MI, Chowdhury TA, Kibria ASMG Investigation of in vitro anti-arthritic and membrane stabilizing activity of ethano extracts of three Bangladeshi plants. The Pharma Innovation J. 2015;4(1):76-80

7. Sofowara A.,1993. screening plants for bioactive agents. In: medicinal plants and traditional medicine in Africa. $\left(2^{\text {nd }}\right.$ edn.) spectrum books Ltd. Sunshine house, Ibadan; Nigeria, pp 81-93.

8. Brand-Williams W, Cuvelier ME, Berset C. Use of a free radical method to evaluate antioxidant activity. LWT-Food Sci Tech. 1995;28(1):25-30.

9. Oyaizu M. Studies on products of browning reaction. Antioxidative activities of products of browning reaction prepared from glucosamine. Jpn J Nutr Diet. 1986;44(6):307-15

10. Singleton VL, Rossi JAJr. Colorimetry of total phenolics with phosphomolybdicacid-phosphotungstic acid reagents. Am J Enol Viticult. 1965;16(3):144-58.

11. Brighente I, Dias M, Verdi G, Pizzolatti G. Antioxidant activity and total phenolic content of some Brazilian species. Pharm Biol. 2007;45(2):156-61.

12. Kumar D, Kumar S, Singh J, Narender, Rashmi, Vashistha BD, et al. Free radical scavenging and analgesic activities of Cucumis sativus L. fruit extract. J Young Pharmacists. 2010;2(4):365-8.

13. Oyedemi S, Bradley G, Afolayan A. In vitro and in vivo antioxidant activities of aqueous extract of Strychnos henningsii Gilg. Afr J Pharm Pharmacol. 2010;4(2):70-8

14. Amorim EL, Nascimento JE, Monteiro JM, Sobrinho TJP, Araújo TA, Albuquerque UP. A simple and accurate procedure for the determination of tannin and flavonoid levels and some applications in ethnobotany and ethnopharmacology. Functional Ecosystems and Communities. 2008;2(1):88-94.

15. Umamaheswari $\mathrm{M}$, Chatterjee TK. In vitro antioxidant activities of the fractions of Coccinia grandis L. leaf extract. Afr J Tradit Complement Altern Med. $2007 ; 5(1): 61-73$
16. Prasad S, Kashyap RS, Deopujari JY, Purohit HJ, Taori GM, Daginawala HF Development of an in vitro model to study clot lysis activity of thrombolytic drugs. Thromb J. 2006;4(14):1-4

17. Hossan SJ, El-Sayed M, Aoshima H. Antioxidative and anti $\alpha$-amylase activities of four wild plants consumed by nomads in Egypt. Orient Pharm Exp Med. 2009;9(3):217-24.

18. Meyer B, Ferrigni N, Putnam J, Jacobsen L, Nichols DJ, McLaughlin J. Brine shrimp: a convenient general bioassay for active plant constituents. Planta Med. 1982:45(5):31-4

19. Jayathilakan K, Sharma GK, Radhakrishna K, Bawa AS. Antioxidant potential of synthetic and natural antioxidants and its effect on warmedover-flavour in different species of meat. Food Chem. 2007;105(3):908-16.

20. Borochov-Neori H, Judeinstein S, Greenberg A, Volkova N, Rosenblat M, Aviram M. Antioxidant and antiatherogenic properties of phenolic acid and flavonol fractions of fruits of 'Amari' and 'Hallawi' date (Phoenix dactylifera L.) varieties. J Agric Food Chem. 2015;63(12):3189-95.

21. Nunes PX, Silva SF, Guedes RJ, Almeida S. Biological oxidations and antioxidan activity of natural products, Phytochemicals as nutraceuticals-Global Approaches to Their Role in Nutrition and Health. 2012

22. Krishnaiah D, Sarbatly R, Nithyanandam RR: A review of the antioxidant potential of medicinal plant species. Food Bioprod Process. 2011;89(3):217-33.

23. Sundararajan R, Koduru R. In vitro Antioxidant Activity on Roots of Limnophila Heterophylla. Free Rad Antioxidants. 2016;6(2):1-10.

24. Yildirim A, Mavi A, Oktay M, Kara AA, Algur ÖF, Bilaloglu V. Comparison of antioxidant and antimicrobial activities of Tilia (Tilia argentea Desf ex DC), sage (Salvia triloba L.), and Black tea (Camellia sinensis) extracts. J Agric Food Chem. 2000;48(10):5030-4

25. Banerjee $A$, Chisti Y, Banerjee UC. Streptokinase-a clinically useful thrombolytic agent research review paper. Biotechnol Adv. 2004;22(4):287-307.

26. Dwivedi S. Terminalia arjuna Wight and Arn: A useful drug for cardiovascular disorders. J Ethnopharmacol. 2007:114(2):114-29.

27. El-kaissi S, Sherbeeni S. Pharmacological Management of Type 2 Diabetes Mellitus: An Update. Curr Diabetes Rev. 2011;7(6):392-405.

28. Onyeche OC, Kolawole JA. Preliminary screening of aqueous extract of the leaves of Securidaca longepedunculata (Linn) for antihyperglycemic property. Niger J Pharm Res. 2005;49(2):18-21.

29. Kwon YI, Apostolidis E, Kim YC, Shetty K. Health benefits of traditional corn beans and pumpkin: In vitro studies for hyperglycemia and hypertension management. J Med Food. 2007;10(2):266-75

30. Urmi KF, Mostafa S, Begum G, Hamid K. Comparative Brine Shrimp Lethality Bioassay of Different Plant Parts of Bauhinia Purpurea L. J Pharm Sci Res. 2013;5(10):190-2. 